This is a self-archived version of an original article. This version may differ from the original in pagination and typographic details.

Author(s): Laapotti, Tomi; Mikkola, Leena

Title: Problem Talk in Management Group Meetings

Year: 2019

Version: Accepted version (Final draft)

Copyright: @ 2019 SAGE Publications

Rights: In Copyright

Rights url: http://rightsstatements.org/page//nC/1.0/?language=en

Please cite the original version:

Laapotti, T., \& Mikkola, L. (2019). Problem Talk in Management Group Meetings. Small Group Research, 50(6), 728-758. https://doi.org/10.1177/1046496419865023 


\section{Problem Talk in Management Group Meetings}

Tomi Laapotti and Leena Mikkola

University of Jyväskylä

Small Group Research

Author Note

Tomi Laapotti and Leena Mikkola, Department of Language and Communication Studies, University of Jyväskylä, Finland.

This research is part of the research project Social Interaction Practices and Wellbeing at Hospital Workplace (TSR112304) funded by the Finnish Work Environment Fund, and has been supported by grants from the Finnish Work Environment Fund and from The Foundation for Municipal Development.

Correspondence concerning this article should be addressed to Tomi Laapotti, Department of Language and Communication Studies, University of Jyväskylä, Finland. E-mail: tomi.laapotti@jyu.fi 


\begin{abstract}
This naturalistic study focuses on problem talk (PT) in hospital management group meetings. The study aims to understand how PT constitutes the hospital organization through the different uses of PT within the meetings, and, therefore, to understand the organizing role of these meetings. The communication as constitutive of organization (CCO) perspective forms the theoretical background of the research. The results of the qualitative analysis show that PT comprises many intertwined tasks that aim to perform the meetings, enhance problem solving, and maintain the relational level of group life. Thus, PT is much more than merely solving problems. In PT, problems are discussed from the viewpoints of the group and the organization. Meetings as an institution and as a nonhuman agent affect organizing because they influence both the group's communication and organizational processes. Future research on groups should develop the use of the CCO concept of nonhuman agency.
\end{abstract}

Keywords: meetings, communication as constitutive of organization, problem solving, nonhuman agency, group communication 


\section{Problem Talk in Management Group Meetings}

Recently, research focusing on group meetings has thrived and becomes a research area of its own (e.g., Allen, Lehmann-Willenbrock, \& Rogelberg, 2015). Meetings have always been popular for collecting group data, but they have mostly been used as arenas or containers for studying other group phenomena, such as decision making or problem solving (Olien, Rogelberg, Lehmann-Willenbrock, \& Allen, 2015; Schwartzman, 1989). In this study, meetings are considered an essential organizational practice and context in their own right, in which the organization is made visible and organized by sharing information and negotiating shared meanings (Boden, 1994; Schwartzman, 1989). This study aims to understand the organizing properties of management group meetings in a hospital organization by identifying how PT, or talk about problems, contributes to organizing. Therefore, to some level, the traditional composition of using meetings as an arena or tool for studying other phenomena has been turned upside down in this study: The analysis of PT is used to understand the organizing properties of meetings in a larger organizational picture.

Why focus on problems? As one of the key activities in organizations, problem solving in groups and teams has become one of the main interests of group scholars. Dewey's $(1910,1933)$ seminal work on reflective thinking formed a fruitful foundation for group research focusing on problem solving and decision making (for an overview, see Frey, 1996). Considerable research in the fields of communication (Hirokawa \& Poole, 1996), social and cognitive psychology (Laughlin, 2011), and related disciplines describes group problem-solving processes from a discursive perspective (Halvorsen, 2010), a functional perspective (Gouran \& Hirokawa, 1996, 2003), a deliberative point of view (Tracy \& Dimock, 2004), and based on structuration theory (Poole, 2013; Seibold \& Meyers, 2007). 
Vast majority of group problem-solving studies have relied heavily on experimental quantitative research conducted with zero-history groups (Laughlin, 2011). In these experiments, groups usually solve rather simple tasks, and the problem is defined, discussed, and solved in situ, without consideration of contextual factors. These studies provide a limited picture of the problems that organizations and their teams face in their everyday operations and of how employees address these problems (Beck, Bourdeaux, DiTunnariello, \& Paskewitz, 2016). Furthermore, problem-solving studies have usually relied on the premise that problems are solved during group situations; these studies focus on the processes aimed at solving the problem rather than on the problem itself or on the other functions that problem-related discussions can present to the group or organization. Hence, problem-solving research relying on ad hoc groups does not fully address the needs of organizations, particularly in terms of wicked problems that organizations need to manage or cope with (Carcasson \& Sprain, 2016; Gerding \& Vealey, 2017). Practically, complex problems are often discussed in groups without the aim of finding a solution, because even if groups cannot solve a problem, it still may need to be addressed to some extent, or at least identified in the first place.

In contrast to the experimental research tradition, discursive studies and studies focusing on group deliberation consider problem solving or decision making a complex and temporally diffused process. For example, Tracy and Standerfer (2003) showed how a group's past, future, and immediate contexts affect the group's discussion as they deliberate. In negotiation and argumentation studies, the focus is often on issue framing (see Putnam, 2016). For example, Craig and Tracy (2005) analyzed how issues came up or were brought up in discussions, and pointed out that although issues are not always thoroughly defined, 
their presence is tied to interactions. Craig and Tracy's results provide guidance for interpreting and analyzing problems that are not always clearly defined during meeting discussions.

Furthermore, Carcasson and Sprain (2016) demonstrated how their practical theory of deliberative inquiry is a purposeful way of dealing with wicked problems or making decisions concerning problems that can be systemic and value laden. They suggested that discussions about wicked problems, even without trying to solve them, can be important for discovering, understanding, and managing these kinds of problems. Altogether, the main conclusion of their study is that groups should engage in deliberative inquiry to intentionally manage wicked problems. In business meetings, problem-solving processes and practices are derived from the contextual factors tied to local organizational structures and practices (Angouri \& Bargiela-Chiappini, 2011). Problems are identified and constructed and their ownership is negotiated in discourse, and meeting participants' accountability can vary in different contexts (Angouri \& Bargiela-Chiappini, 2011; Castor, 2007). Leighter and Black (2010) investigated the functions of raising questions in public deliberative meetings, and demonstrated how raising questions was not only about asking questions but also more widely about "achieving clarity, helping to structure conversation, and adding information that doesn't tell the whole story" (p. 563), as well as about creating relational-level collaborative communication. We continue this notion by considering PT as a process that can also serve other functions outside the actual problem-solving or decision-making processes.

The present study examines organizational problems and why they are discussed in management group meetings. Using a holistic approach and a constitutive view of 
communication, the aim is to understand the organizing roles of PT and meetings. In earlier studies, problems have been explored either as issues with clear solutions in ad hoc groups, or as complex and temporally dispersed processes focused on how problems are constructed, framed, managed, or solved.

\section{Problem Talk Conceptualized}

This study focuses on the organizing role of management group meetings through PT. A problem is defined here as "a discrepancy between a current less desirable and a future more desirable state" (Laughlin, 2011, p. 1). In this study, PT is conceptualized as talk about problems or problem-related interaction. PT is not postulated as positive (e.g., Robinson \& Timperley, 2007), negative (e.g., Boren, 2014), or neutral. Moreover, PT is not viewed in terms of certain phrases or words but rather as a broader topic of group discussions. The premise of this study is that problem solving in natural groups is a complex, temporally diffused, and dynamic process (Hoelscher, Kramer, Nguyen, Cooper, \& Day, 2016; Tracy \& Standerfer, 2003). As all interactions concerning problems are examined, PT is possibly not always about problem solving. Thus, another premise of this study is that PT can have functions for a group or for a discussion other than problem solving; consequently, PT can constitute something else for the group and for the organization other than solutions (Leighter \& Black, 2010).

Notably, because of this broad definition of PT, the talk examined in this study is, at the same time, meeting talk. Meeting talk has several functions, which include information sharing and operational or procedural coordination (Hollingshead, Costa, \& Beck, 2007; Tracy \& Dimock, 2004; Wittenbaum, Hollingshead, \& Botero, 2004). This study analyzes the 
role of problems within the more generic frame of meeting talk, or why problems are brought to the discussion in the first place.

\section{Theoretical Framework}

To address the challenge of understanding the organizing role of PT in meetings and how meetings organize the organization, we apply the communication as constitutive of organization (CCO) perspective (e.g., Brummans, Cooren, Robichaud, \& Taylor, 2014; Putnam \& Nicotera, 2009). The CCO perspective views organizations as processes constituted in interactions (Putnam \& Fairhurst, 2015). Although the CCO perspective is a rich viewpoint in the study of communicative processes in meetings (Cooren, 2007), it remains underutilized in group research. From the CCO perspective, PT constructs the social realities of participants; at the same time, these communicative processes constitute the organization (Castor, 2005). In this study, the CCO perspective guides the analysis toward examining how PT constitutes the organization in group meetings, and, therefore, toward understanding the organizing role of these meetings.

In the Montreal school of $\mathrm{CCO}$, agency is conceptualized as the ability to make a difference (see Cooren \& Fairhurst, 2009). From the CCO perspective, agency is not limited to humans. Following Latour (2005), the Montreal school of CCO (see Brummans et al., 2014; Schoeneborn et al., 2014) views rules, statuses, documents, objects, worldviews, and institutions as actors that affect (or do not affect) their environment in the same way as human actors (Cooren \& Fairhurst, 2009). Furthermore, agency is relational and "always involves capacities of other beings and things" (Cooren, 2018, p. 142). According to Cooren (2018), acting is always "acting for, with, and through" (p. 142). Cooren (2010, 2015b) uses the metaphor of ventriloquism to describe how a nonhuman agent makes a human agent say 
or do something, or vice versa. In an earlier study, Castor and Cooren (2006) demonstrated the important role of nonhuman agents in problem formulation. Their focus was on blame, problem definition, denial, and solutions, and they concluded that the selection among agents is a key process in problem formulation. Castor and Cooren concluded that nonhuman agency can be inferred from the actions of meeting participants (implicit) or can be created or negotiated by participants (explicit). In short, from the CCO perspective, PT in meetings constitutes the problems and the organization, and it is affected by human and nonhuman agents.

\section{Meetings and Organizing}

From the CCO perspective, organizations are conceptualized as networks of communication episodes (e.g., Blaschke, Schoeneborn, \& Seidl, 2012). Meetings can be seen as central nodes in this kind of network because they are key occasions for organizing (Bargiela-Chiappini \& Harris, 1997; Boden, 1994). In the present study, meetings are not considered merely as containers for problem-solving processes but as something that constitute the organization in their own right (Putnam \& Fairhurst, 2015; Tracy \& Dimock, 2004). In meetings, groups can create and solve problems, as well as develop a sense of togetherness, while maintaining or challenging organizational values (Tracy \& Dimock, 2004). Interactions in meetings are shaped historically and situationally, and they combine the views of planners and attendees (Tracy \& Dimock, 2004).

Moreover, Schwartzman (1989) argues that meetings produce the organization, not vice versa. Boden (1994) continues that organizations produce and reproduce themselves through interactions in meetings. Schwartzman $(2015,2017)$ recently stated a need to study meetings as a systemic whole within organizations and not as single events (see Duffy \& 
O’Rourke, 2015) or as individual-centered events. According to Schwartzman (2015, 2017), meetings can acquire agency, and by focusing on this agency, we can learn more about how meetings affect actions during and outside meetings. Furthermore, meetings are often characterized as rituals, and organizational rituals are suggested to have their own agency (Koschmann \& McDonald, 2015). From the CCO perspective, meetings can be considered nonhuman agents because meeting practices, minutes, and agenda make a difference (see Duffy, 2016). In this study, meetings are examined as a systemic whole that can carry nonhuman agency, so the key organizing role that meetings have been given in earlier studies can be understood more thoroughly. We aim at adding knowledge to the question proposed by Schwartzman (2017), how do meetings “make things happen?” (p. 174), by analyzing the organizing role of PT.

\section{The Context of the Study}

\section{Aim of the Study}

The present study examines PT in naturally occurring organizational settingsmanagement group meetings. From the $\mathrm{CCO}$ perspective, we study how the organization is constituted in these meetings, and how PT constitutes the social reality of the group and the organization in which the group is embedded. We do this by examining the different tasks of PT during management group meetings. Our aims are to (a) understand how PT constitutes the hospital organization in management group meetings and (b) understand the organizing role of these meetings. The following research questions guide the analysis process:

RQ 1: Why are problems brought to meeting discussions?

RQ 2: How do meetings act as an organizing arena or agent through PT? 
The first question focuses on the tasks of PT, and the second question focuses on the organizing role of management group meetings.

\section{Hospital Management Groups}

Studies have shown that hospital management groups have an important role in a hospital's management systems (Viitanen et al., 2011) and information flows (Laapotti \& Mikkola, 2016). In addition, hospital management group members perceive their meetings to be important for their work as managers (Viitanen et al., 2011). Management group meetings in hospitals are usually formal, and organizational roles and hierarchies are visible in the interactions (Iedema, Degeling, \& White, 1999; Laapotti \& Mikkola, 2016).

The context for this study is a large public hospital in Finland. Public hospitals in Finland have management groups at three different organizational levels, and typically, only the highest level group has formal decision-making power. This study focuses on the two lower levels, where the executive director (of the middle-level management group) or the director (of the lowest level management group) has managerial responsibility and makes the decisions, and where groups have no formal power or decision-making responsibility. These groups are expected to share information, and support the director in his or her tasks, but they are not formed for decision making (for more information about the Finnish health care system and hospital administration, see Simonen, Viitanen, Konu, \& Blom, 2009).

\section{Data}

The data consist of the video recordings of 10 hospital management group meetings from the executive director and director levels, five from each level. The video recordings were made using a $360^{\circ}$ panorama camera, and one or two researchers were present at each recorded meeting. The members of the operational area $(\mathrm{OA})$ management group were unit 
managers, and the chair was the executive director of the area. There was also one representative of the nursing staff. Each recorded OA meeting was composed of six to 10 participants, and visitors, informing the group about wider organizational issues attended two meetings. The operational unit (OU) management group members were the chair, who was also the chief physician and director of the unit; the head of the department; nurse managers; and members of the nursing staff. Six to eight participants attended these meetings, and a secretary was present at both OA and OU meetings. All group members gave their written consent to participate in the research project; visitors gave their oral consent. The OA meetings varied in length from just less than $1 \mathrm{hr}$ to almost $2 \mathrm{hr}$, and the OU meetings lasted from 45 to $70 \mathrm{~min}$. The full length of the video data was $12 \mathrm{hr} 19 \mathrm{~min}$. All data were transcribed verbatim.

Both groups met once a month, and participants were informed beforehand by email about the meeting agenda. The data were collected during the fall of 2012 and spring of 2013. A major organizational change process started during this time to replace the current hospital building, with a new building within 5 to 6 years. This forthcoming change, combined with the challenging economic times, pressured the hospital to save money and reorganize its functions more efficiently.

\section{Analytical Strategies}

The first author performed the analysis and discussed the interpretations with the second author throughout the analysis process. All problem-focused episodes of the discussions were identified from the data transcripts. An episode was defined as a segment of discussion in which the main topic was a problem. Such episodes ranged from one speaking turn to several minutes of group discussion. Quite often, it was explicit that a certain issue 
was a problem (the word problem was used); sometimes, it was interpreted that an issue under discussion could be considered problematic (see Craig \& Tracy, 2005). If a discrepancy emerged between a current less desirable state and a future more desirable state, it was interpreted as PT. Meeting talk that concentrated on information sharing about nonproblematic issues, coordination of work, or meeting procedures was not included in this study. Across 307 single-spaced pages of transcriptions, 143 episodes of PT were identified. The first author translated into English the data excerpts chosen for use in the "Findings" section.

All PT episodes were analyzed twice. The first analysis round adhered to the principles of qualitative content analysis (Braun \& Clarke, 2006; Schreier, 2014) and focused on the tasks of PT. First, emergent coding (Fairhurst \& Uhl-Bien, 2012) was used to identify the task(s) of each PT episode. One PT episode could be quite long and include several tasks. The interpretation of the tasks was based on what was said (e.g., if it was explicated that help was needed to solve a problem or "I tell you this because..."), the meeting agenda (e.g., "current issues"), or the communicative reactions of the group (e.g., humorous reaction, engaging in problem solving, no reaction). Second, identified tasks were arranged under higher level task categories described in Table 1. The codes and categories were formed inductively as the analysis progressed. The entire data set was read through several times before the primary labels were created.

The second analysis round examined the PT episodes through the lens of organizational discourse analysis to answer the second research question and to understand the organizing role of meetings (Cooren, 2015a; Fairhurst \& Uhl-Bien, 2012). The analysis 
focused on how PT executed the organizing properties of meetings through human or nonhuman agencies.

\section{Assessment of the Study}

Video recording can influence those recorded. In this case, the groups acted slightly more formally during the earlier recorded meetings than in the subsequent ones. This is mainly visible in the formal way the participants asked for the floor, which rarely happened in later meetings. The participants' behavior normalized as the observations continued (Frey, Botan, \& Kreps, 2000). The data set is appropriate in size because the meetings were routine meetings, and they were similar to one another, and it is unlikely that collecting more data would have changed the results. However, future investigations should compare data from different kinds of groups. The study focuses on the meeting as an institution, and meetings are relatively similar between contexts (Schwartzman, 1989). Thus, it can be argued that the results are transferable to different contexts (Lincoln \& Guba, 1985), particularly to groups operating within public organizations. The findings are reported below. The content of the discussions is adjusted to retain the anonymity of the OA and OU members, and the data excerpts are anonymized using general terms of hospital work or pseudonyms.

\section{Findings}

\section{The Tasks of Problem Talk}

PT constitutes the organization through several tasks in hospital management group meetings (RQ1). These tasks (performative, problem solving, relational) were usually simultaneous; thus, one, two, or all three tasks could be evident in one PT episode. Therefore, PT was used to perform the administrative meetings, enhance problem-solving processes, and for relational functions. Table 1 describes the tasks of PT and provides some examples. Next, 
to scrutinize how meetings act as an organizing arena or agent through PT (RQ2), the meetings' organizing properties and nonhuman agency are examined through the tasks of PT. Table 1

Tasks for Problem Talk

\begin{tabular}{|c|c|c|}
\hline Main tasks & Explanation & Example \\
\hline Performative task & $\begin{array}{l}\text { Executing the official } \\
\text { tasks of meetings, which } \\
\text { are information sharing } \\
\text { and supporting } \\
\text { management actions. } \\
\text { Sometimes, performing } \\
\text { these tasks involved a } \\
\text { play-like nature. }\end{array}$ & $\begin{array}{l}\text { - Performing the agenda by reporting } \\
\text { or announcing a problem } \\
\text { - Forming a shared understanding of a } \\
\text { problem so that the issue can be } \\
\text { presented elsewhere } \\
\text { - Making a problem visible and thus } \\
\text { official in a proper administrative } \\
\text { channel } \\
\text { - Getting directions or support }\end{array}$ \\
\hline $\begin{array}{l}\text { Problem solving } \\
\text { task }\end{array}$ & $\begin{array}{l}\text { Participating in problem } \\
\text { solving processes, either } \\
\text { by making sense of the } \\
\text { problem or by solving it. }\end{array}$ & $\begin{array}{l}\text { - Reducing uncertainty } \\
\text { - Trying to understand the background } \\
\text { of a problem } \\
\text { - Solving a problem } \\
\text { - Enhancing a problem solving process } \\
\text { - Checking if a problem is noted and } \\
\text { ensuring that something will be done }\end{array}$ \\
\hline Relational task & $\begin{array}{l}\text { Building cohesion or } \\
\text { positioning the group. }\end{array}$ & $\begin{array}{l}\text { - Seeking support } \\
\text { - Differentiating the group from its } \\
\text { environment } \\
\text { - Complaining } \\
\text { - Humor }\end{array}$ \\
\hline
\end{tabular}




\section{Performing Meetings through PT}

PT constitutes the organization, as it is used for performing meetings in different ways. Occasionally, these meetings become a type of administrative play or drama; the goals of the management group meetings, meetings as an institution, and the meeting agenda make the groups act in a certain way. The two main goals of these meetings indicated in organizational rules were to share information and help the managers in their work. As a part of the information-sharing goal, meeting was performed by reporting about problems according to the current issues part of the meeting agenda. Excerpt 1 shows how none of the participants commented on the reported problem. Meeting members are identified and differentiated by the labels, for example, of M1 (member 1) and Chair.

\section{Data excerpt 1: OA management group meeting 1}

M6: Well, then an acute one: renovation at one of our departments will end all operations by week 41, which is next week. We got the info on Friday, and it was and still is very unclear, and we have not received an answer on whether it is going to be for one or two weeks - It was—ok, so how to inform people—time is running out.

Chair: Ok—ok, next subject.

Often, the problems reported formally were ongoing issues concerning, for example, the availability of workforce, which was mentioned in almost every meeting. In OA Meeting 3, the chair reported the following: "There's nothing special happening [in our OU]; we still have two vacancies, and no one has been interested in them. The show goes on as usual. The next unit." In such cases, it is not surprising that the group does not discuss the problem they have heard repeatedly. However, as Data Excerpt 1 demonstrates, sometimes, the group does not discuss even acute short-term problems. This kind of reporting about problems is not 
connected to problem solving, as there is no discussion. Although it is not problem solving per se, reporting is an important characteristic of these meetings.

It is also possible that the meeting or, more specifically, the meeting agenda as a nonhuman agent (Cooren \& Fairhurst, 2009) restricts the discussion here because these kinds of problems related to day-to-day work were raised in the part of the agenda addressing current issues, and are not usually discussed in these meetings. Thus, it did not seem to matter whether the problem reported was acute or not. Organizational structures between units can also limit discussion because in hospitals, the culture of respect for others' expertise is strong, and can inhibit discussion. If advice is given, it can be interpreted as an expression of doubt in one's ability as a manager or clinician. This kind of reporting without discussion also promotes understanding of the organization, as meeting participants obtain information of what is going on elsewhere in their OA or unit. The organization outside their everyday work becomes existent to the participants through the meeting, and, thus, meeting interactions constitute the organization. Because these interactions are meeting initiated (i.e., the agenda is performed by the participants), it is the meeting that functions as an organizing agent for, with, and through the meeting participants.

The second formal goal of the meetings is to obtain support in one's work as a manager. Data Excerpt 2 highlights how this goal initiated PT, as M3 starts a discussion concerning the worries of his or her employees and seeks support through his or her representative role in the meeting:

\section{Data excerpt 2: OA management group meeting 2}

M3: The staff is quite puzzled with the new hospital and what is going to happen to them. I have said in our weekly meetings that many times, what I'm reading in the 
local newspaper is news to me too-and that we are informing them as much as we can, but there is always something in the local newspaper that I haven't informed them about because I have not known about it myself.

Chair: It is true, and when the employees-[see] it says in the newspaper that there will be $10 \%$ less staff-

M5: For them, it is 25.

Chair: So we have to repeat that the health district still has the contract, and it wants to stick with it, that no one will be laid off for financial reasons.

M3 and M5 (simultaneously): Hmm

Chair: Because this $10 \%$ reduction in staff is the first thing they are afraid of, and if it is true, it will happen because of normal retirements and so on, this $10 \% \ldots$

M5: Yeah. Well, I think this new hospital initiative as a whole, that there is heavy pressure on [certain functions of the hospital] to develop. And on numbers and making the work more efficient. So, I think it is the core task of the hospital to guide the change.

Chair: OK. It could be said that this new hospital initiative at least started from a patient orientation and from the processes surrounding patient care.

M5: Hmm

Chair: OK, then, M2; you asked [for the floor]. (M2 raised his/her hand earlier.) M2: So, the $10 \%$ means work contribution, not people but work contribution, and it is an average. We have to manage with $10 \%$ less work contribution in the future. In practice, it means that in some units, the work contribution decreases, but in some units, it can increase. 


\section{M3: Hmm}

Chair: Yes.

M5: I think so, too.

M2: So that is what you should tell the personnel that it doesn't mean that every tenth person will go but that the work contribution decreases and, in some cases, even increases, when the core process [of the hospital] is highlighted, like what M5 said. Chair: Good. I then suggest that the issues from the management group of the health district be discussed in our next meeting.

In Data Excerpt 2, the group uses the meeting as a means for organizing, that is, for obtaining support to solve a practical problem involving their managerial work. By building a shared understanding of the employees' concerns, the group supports M3 as a manager and makes suggestions on how to deal with the situation. M3 fulfills the representative role of a group member and obtains information to inform the employees. Hence, the problem-solving task of PT is also met. It is likewise possible that M3 brings these problems to discussion to obtain social support (Laapotti \& Mikkola, 2016); therefore, the relational task of PT is evident in this excerpt. Overall, the forthcoming changes are shown here as something that will happen regardless of what this group or its members do, which highlights the powerlessness of the group; they just need to adjust to these changes by solving the local problems that emerged from global changes. In the end, the chair decides to skip one item on the meeting agenda, which shows again that the group can exercise its agency against the agency of the meeting agenda. 
Occasionally, the meeting initiated play-like PT. In Data Excerpt 3, the PT starts when M2, the acting chair (and nurse manager), introduces the other issues section of the agenda.

\section{Data excerpt 3: OU management group meeting 3}

M2: Do you have any other issues?

M9: Yes.

M2: Ok.

M9: You are welcome.

M10: Ok-So, on behalf of a colleague, about substituting in the health care centers. I will read this (holds a paper), so I will get it right, or as he/she has phrased it.

First of all, M9 (the head of the department) is the one who answers M2's question and then gives the floor to M10 (a nursing staff), so it seems that M9 already knew that there were other issues. M10 reads a long text describing the problem experienced by substitutes, whose working days are getting longer because of traveling distances, but the compensation does not account for this; therefore, finding voluntary substitutes, when needed, has become difficult. M10 talks on behalf of the working community about an issue that is considered problematic. The group starts discussing the problem:

\section{Data excerpt 3 continues}

M10: The time spent traveling should be counted as working hours because the days can be extended by several hours.

M9: It is good that you brought this up.

M2: Yeah.

M9: Very good. 
M2: It is good. The person who wrote the letter also discussed it with the chief physician, who was under the impression that the time spent traveling was already counted as a part of the working time.

Here, it becomes clear that M2 as a nurse manager already knew about the issue. M2 starts explaining how the problem solving has progressed so far. M2 has discussed this issue with the chief physician, who told M2 to approach the human resource (HR) department of the hospital. M2 has already written and sent a letter to the HR and starts reading the letter. The letter explains the situation, and midway to the end of the letter, there is a line saying that "nurses have written a letter for the OU management group meeting, explaining that they want compensation for this working time situation from the hospital." After M2 has read the letter, M9 starts a 9-min problem-solving discussion by asking what the HR department's stand is, as of the moment. During this discussion, the group speculates about various solutions. At the end of this discussion, M2 brings the topic back to the meeting situation:

\section{Data excerpt 3 continues}

M2: So, this is in progress. Let's not write anything in the minutes except for this letter from the nurses-

M9: There was a discussion about the topic, so-

M2: There was a discussion about the topic, and the discussion will continue. So, let's not write everything in black and white.

This PT episode brings to the foreground many insights concerning meetings as an administrative performance or play, and it is the nonhuman agency of meetings that enhances this kind of behavior. First, it appears that everyone participating in the meeting already knew the details of the issue; yet, it was still presented as a new issue for the meeting's sake. 
Second, the actual problem-solving process was already in process because M2 sent a letter to the HR department, so neither this meeting nor this episode of PT contributes to the solving of the problem. The problem-solving process and the administrative PT process are separated because of the meeting practices of the hospital. Third, in the letter sent to the HR department, it was mentioned that the nurses had written a letter for the OU management group meeting, so the tense is false, which substantiates the play-like composition of the situation. Fourth, although this group has no power to solve the problem, they have a lengthy problem-solving discussion. Rationally, the group could decide what to write down, but they have (from the viewpoint of problem solving) a pointless discussion, which indicates that the group considers the issue important. This conversation segment shows that the group does not only submit to the nonhuman agency of the meeting because the problem-solving discussion is for the group, not for the meeting or for the organization. That is, the group executes its own agency as they engage into problem-solving discussion that is not needed from the organization's viewpoint. Fifth, M2 decides that this discussion should not be detailed in the official minutes of the meeting, which means that it stays within the group, thus proving that the content of the discussion had little value in terms of management or problem solving.

In the end, the discussion of this problem under the other issues part of the meeting agenda was to ensure that the issue is brought to the official administrative channels of the organization - the meeting minutes. This PT episode can, thus, be viewed as a play or a drama written by the hospital organization that the group is performing for the organization. Through minutes, meetings materialize as a part of the physical organization (Evans, 2017), and the organization expects its meetings to produce specific documents. Therefore, the meeting acts as an agent that affects the way the group communicates and, at the same time, 
as an agent that organizes the organization's formal structure through minutes. In their study on board meetings in a public-sector organization, Freeman and Peck (2007) found that theater-like symbolic behavior can help the group fulfill its task goals, which seems to apply to the meetings studied here because the group shares information strategically (Hollingshead et al., 2007).

In comparison, in Data Excerpt 3, the group uses the meeting as a venue for making something official in the way the organization expects: They act as they do mostly for the organization. The OU can also use its management group meetings as a venue for sending messages to the administration. In OU Meeting 1, M1 and M2 (both nurse managers) raise a problem concerning an additional position of an employee that is needed, but the administration has not given permission for recruitment yet. They describe what kinds of challenges the employee shortage causes, and, finally, the chair concludes, "So, now, hiring an extra employee must be put on the top of the agenda." Many times, the groups problematized (i.e., constructed problems in their interactions) current situations to generate the desired effect, such as recruitment. These kinds of episodes of PT are again performed to achieve something mentioned in the official organizational documents, but this time, the OU or OA is the initiator of the discussion and not the organization (as in Data Excerpt 3). Thus, the meeting acts as a ventriloquist device (Cooren, 2015b) for both the organization and the participants: The group makes the meeting talk and vice versa. At the same time, the aim here is to solve a problem, and this is achieved by using other problems caused by the current problem as a rhetorical device to make a point.

In summary, the organizing role of the performative task of PT centers on sustaining organizational practices and structures, as well as making sense of the organization through 
information sharing. The nonhuman agency of the meeting agenda guides meeting interactions, and the nonhuman agency of the meeting itself is harnessed both by the organization and the group, so the views of both planners and attendees are addressed (Tracy \& Dimock, 2004). Many times, these performances of PT do not contribute to problem solving at all, but sometimes, they do.

\section{Enhancing Problem Solving through PT}

Not surprisingly, the PT in the meetings enhanced organizational problem-solving processes (as already seen above), and some local, tangible problems were also solved, if only partially, during the meetings. Simple problems with technology (e.g., PowerPoint) were addressed immediately. Usually, the solution was some kind of advice on how to proceed with an issue, as in Data Excerpt 2. Furthermore, the information shared resulted in shared understandings of the problem at hand and deepened the group's understanding of the problem's background, thus enhancing the overall problem-solving process. Schwartzman (1989) argued that meetings are held to rationalize decisions. In many cases, this is exactly what the management groups studied here were doing and could do because of their powerlessness: They rationalized problematic situations by making sense of them. In addition, Hoelscher et al. (2016) showed that rationalizing problem-solving processes was one of the triggers behind the problem-solving discussions they studied.

\section{Data excerpt 4: OA management group meeting 3}

Chair: Indoor air-Indoor air problem of M3's unit. Have there been any headaches? M3: Well, apparently some—-some people are taking more antihistamines than before,- - but there has not been any sick leave, but- 
Chair: And they continue to stay in their old rooms-(M3 nods) How about M1's unit? You also had indoor air issues-

M1: We have one-one room is out of order.

Chair: Is there going to be a renovation?

M1: There is-well, they promised that it will be fixed this year.

Chair. OK. Then under other issues, we have ...

Here, the chair uses the meeting as a tool for overseeing organizational problemsolving processes by checking whether any progress has been made concerning the processes related to the problems known by the participants. Thus, Data Excerpt 4 is about building an understanding of an organizational process while it is progressing (cf. Hoelscher et al., 2016; Schwartzman, 1989). In Data Excerpt 5, the problem is that two of the managers are uncertain of the length of the employment contracts and how temporary contracts can be justified.

\section{Data excerpt 5: OA management group meeting 2}

M3: I am trying to get this clear; I asked you before regarding the length of the employment contract.

Chair: Well, the operation will continue, so don't make it too short. Make it half a year or a year. We can change it [to a continuing contract] if we can get the actual position confirmed by the administration.

M3: OK.

Chair: Make it a year.

M3: And I sign it?

Chair: You sign it. 
M1: Um, Chair, in the same vein-should we make it a year also for this [title of an employee]?

Chair: Yes, yes, it is a continuing activity, not a test anymore-

M1: But we just make it like—ok.

M3: Should we make this forthcoming strategic planning an argument for the temporary contract if they ask why we have someone without a vacancy?

Chair: Yes. Send the papers to the office, so the secretary and I can take a look and write down the arguments.

M1: Hmm

Chair: If I would sign them?

M1: Good.

Chair: So, there will be only one villain. Ok. Is there anything else that is important? In this excerpt, the underlying problem is that clinical work and administrative paperwork are not coherent: M3 and M1 already have new operations running and employees hired, but the permanent positions of these employees are not officially confirmed yet. As the operations are planned to be permanent, there should be some reason provided why the contracts are not permanent. The problem (writing and signing the contracts) emerges from one simple question and becomes more complex because the contract length is not the only issue. Moreover, there is the underlying administrative problem (conflict between clinical and administrative work), so the chair solves the current issue by taking responsibility for sorting out the paperwork. By doing so, the chair organizes the unit's organizational practices. However, this group will not solve the bigger administrative problem, which is the cause of the more tangible problem with the contracts. In many cases, a group solves some discussion- 
based (emerged) local problems, but the more global (wicked) problem (Carcasson \& Sprain, 2016) remains to be addressed. Almost all administrative or clinical problems were solved after the meeting situation, and the groups adapted to their powerlessness through partial solutions, as in Data Excerpt 5.

In Data Excerpt 6, the chair and M1 plan their upcoming presentation in a planning meeting, where the needs of employees and other resources are asked by the top management.

\section{Data excerpt 6: OA management group meeting 1}

Chair: ... and [a certain unit] has started new operations-yes, M1?

M1: About this-it was discussed earlier that the operation will continue even if the vacancies are not formally established yet. So, can we put that on the table here?

Chair: Yes, we can. You mean actual?-

M1: An actual person who can work there.

(Chair and M1 discuss briefly about the title of the person.)

Chair: Ok-so M1's unit has this kind of issue. And M3's unit has a similar kind of issue, right?

M3: Yes, the [title of the person].

Chair: Yeah, but there are two things missing: the administrative decision concerning the position and the money. We will talk about these under problems and shortcomings [in the forthcoming meeting], under HR.

Here, the group forms a shared understanding of the issue at hand (i.e., lack of an official position for an employee) and agrees that it is a problem (Craig \& Tracy, 2005). This discussion demonstrates how the only thing the group can do is decide that there is a problem 
that should be introduced to those who can solve it. This exemplifies how different groups within an organization can participate in problem solving or decision making across space and time, or, as Tracy and Standerfer (2003) established, how decisions could be about future decisions. According to Schwartzman (1989), meetings throughout the organization are important for organizing actions, and the above excerpt demonstrates how different meetings are linked in organizations, and how organizational problem solving appears in interactions across meetings. Only the bigger picture shows this meeting's indirect participation in organizational problem solving.

The organizing role of these meetings was also evident, when in OA Meeting 1, M5 announces that "[ $\mathrm{t}]$ he financial administration has given me a strong suggestion [laughs] to arrange a meeting concerning the changes in premises and my unit.” Then, M5 enumerates the people who should be invited to this meeting to solve the problem, and agrees how to proceed with the chair and the secretary. The PT in this management group meeting is for arranging another meeting. The solution to the problem is to call for a meeting, which implies that meetings can solve problems. It is typical that meetings produce more meetings (Schwartzman, 1989).

The problem-solving task of PT organizes by enhancing problem-solving processes, producing solutions, and rationalizing organizational processes. Although many problems are not solved during these meetings, these meetings are a part of the organization's problem solving. As meetings are connected to one another and form a network for problem solving, they can be seen as having nonhuman agency that can help in problem solving for, with, and through the meeting participants. 


\section{Relational Organizing through PT}

On many occasions, PT carried out relational tasks, which were evident when the group positioned itself in relation to the surrounding organization and when cohesion was built, for example, using humor or in supportive interactions. Relational tasks were also evident in sensemaking, in which shared meanings were created, and when PT created usversus-them situations, which allowed the group to feel whether their situation in the forthcoming organizational change was easier or more difficult than that of the other units. In an earlier study, Peck, Perri, Gulliver, and Towell (2004) showed the social importance of the board meetings they studied, compared with rituals, even when the actual task goals were not achieved. The powerlessness of the group was one specific reason for engaging in PT.

\section{Data excerpt 7: OA management group meeting 3}

Chair: Then about HR planning. The goal is to reduce the work contribution, the wage costs, to the 2013 level. And there was again a very rich conversation about how we can decrease our overall costs when the same workload is still expected to be done ... In [another operational area within the hospital], they perhaps can do something; they have reduced the use of substitutes and so on. They have also rearranged some positions, some nurses, when the overall clinical workload decreased a little. But for us, it is hopeless, unless there are some structural changes. Like this. Well, that's all about that. Let's move to the current issues of the units.

The chair describes an organizational problem and lets the group know that she is aware of the difficulties involved in the situation. The chair also compares this OA with another OA to show that there is little they can do in this particular area. This kind of-we know this is hard and stupid, but we just have to wait, see, and cope-PT episodes can be 
viewed as therapeutic for the group because, many times, they built a shared understanding of the situation and positioned themselves in relation to the problem. This is eminent in the next example, where the group uses humor to position itself in relation to a problem as they discuss the waiting times for certain treatments:

\section{Data excerpt 8: OU management group meeting 4}

M4: It is a bubble that is getting bigger and bigger, and soon, it will explode.

Chair: Yes, you see, and we have to do all this with less expenses and fewer employees than before.

M4: Right.

M7: That sounds like a good equation.

Chair. OK, let's get back to those figures.

Sometimes, PT evoked humorous discussions, in which the problem was the source of humor, indicating that the problem was so serious or so far from the group's power to solve that humor was the only way they could cope with the situation. This use of humor was also evident when the group discussed the aging population, higher life expectancies, and the more expensive care for the last years of human life in relation to the expectations of lower costs and money-saving goals set by politicians and the hospital administration.

Furthermore, PT can reveal the moral assumptions of the group (Castor, 2007), and in Data Excerpts 7 and 8, the group differentiates itself from the organization by making it clear that it does consider some problems serious, although it seems that the organization perhaps does not take these problems seriously enough. In these cases, where contradictions exist between the values of the group and those of the organization, the group negotiates its boundaries and levels its interdependency with its surroundings, or it negotiates and 
constructs agencies to whom it saddles the problem. In Data Excerpts 7 and 8, the chair frames the problem, in its current form, as unreachable or as someone else's problem.

Data Excerpts 7 and 8 can also be seen as complaining because there is no effort for constructing solutions. Complaining is typically considered a negative or counterproductive behavior in group meetings (Kauffeld \& Lehmann-Willenbrock, 2012; Kauffeld \& Meyers, 2009) and for individuals (Boren, 2014). However, complaining as a form of PT can also have positive effects on the group. Complaining together builds cohesion and tightens the group's bonds, as well as positions the group in its surroundings. In many times, the problem is elsewhere and not within the domain of the group. The powerlessness of the group drives its members to complain; they rationalize the situation by making it visible in interactions that they are aware that the situation is problematic, or that the current way of doing things is destructive, but because they have no power to solve the problem, they express their consensus by complaining. Complaining in this situation can, therefore, be described as positive relational-level interaction by its supportive function.

The relational task of PT organizes by constituting the groupness of the management groups through building cohesion and defining the group's position within the organization and in relation to the problem at hand (also Tracy \& Dimock, 2004). The meetings' organizing role is to enable the participants to come together and discuss, and because of the powerlessness of the groups and their meetings, the relational task of PT is of a certain kind, as presented above.

\section{Discussion}

The results show that PT constitutes the organization by constructing the meetings (the performative task), the solutions (the problem-solving task), and the relationships (the 
relational task). These processes are intertwined and usually carried out simultaneously as a part of the genre of meeting talk. The problems, the discussion of the problems, and the tasks of such discussions are complex in a hospital management group setting; PT is so much more than merely solving problems, and in many cases, PT has nothing to do with solving a problem. In addition, the relationship between PT in group meetings and organizational problem solving and decision making is complex. Although the management groups studied were not meant to make decisions, they are a part of the decision-making and problemsolving structures of the organization. Nevertheless, many of the problems discussed during the meetings are solved in higher level management group meetings, specially focused work groups, or informal gatherings. Overall, the findings substantiate the argument that meetings are fundamental occasions for organizing (Boden, 1994) and do not merely serve as containers for PT. Next, the organizing role of these meetings is examined from the viewpoint of nonhuman agency.

\section{Nonhuman Agency of Meetings}

This study shows the value of focusing on the agency of meetings (see Schwartzman, 2015, 2017). The key role of meetings in organizing enables conceptualizing meetings as executing nonhuman agency for, with, and through meeting participants (see Cooren, 2018). The results of this research showcase the nonhuman agency of meetings in many ways. The meeting as an institution and how it is used in this hospital has a significant effect on groups' communication. For example, one of the main reasons for the emergence of PT was the meeting itself; the overall goals of the meetings set by the organization and the meeting agenda drove the discussion, usually implicitly (see Castor \& Cooren, 2006), through the performative task of PT. Thus, the meeting itself or its ritualistic characteristics (i.e., 
established meeting practices) can be viewed as an agent (also Duffy, 2016; Koschmann \& McDonald, 2015), and the meeting agenda is considered an agent because it makes the group behave in a certain manner. This is the first way of viewing the agency the meeting exercises for, with, and through the meeting participants. The meeting makes a difference within the meeting situation because it has an impact on the participants' interactions.

The second way to view the meetings' nonhuman agency is to focus on their organizing properties from the point of view of the organization from a temporal perspective. The findings show that meetings make a difference in maintaining organizational structures and practices, the stability of the organization, problem-solving and decision-making processes, the organizing of work and responsibilities, other meetings, and so on (see also Cooren \& Fairhurst, 2009). Although the groups examined did not have the formal power to make decisions, their meetings are a part of the decision-making structures of the hospital: systemic, organization-wide problems are made sense of and, to some extent, deliberated in these meetings. Discussing wicked problems can also be an important part of managing them (Carcasson \& Sprain, 2016).

These groups work together as a group only in their meetings, different meetings are connected to each other throughout the organization, and from the $\mathrm{CCO}$ perspective, the organization is a network of communication episodes. Moreover, reflecting on the notion of Leighter and Black (2010) that sometimes the discussion raises the question, in this case, it is the meeting, not individual participants, that initiates PT through the agenda. We argue this because the discussions the groups have are happening only because of the meeting itself, and these discussions only matter when they happen in meetings. The findings of this study, therefore, suggest that it is the meeting (i.e., the group situation), not the group or its 
members per se, which makes more difference. Of course, there would not be a meeting without participants, but theoretically, it is worthwhile to focus on the meeting itself, not on individual participants or the group detached from its institutional and situational contexts. This is how we can gain understanding on why groups do what they do. Because of its status and agency, the meeting emerges as a more important unit of analysis than the group, and because of its constitutive properties, meeting communication is the key process to investigate (see also Tracy \& Dimock, 2004). In the case of PT, the meeting initiates certain types of PT, and it is essential that this PT takes place in meetings, not elsewhere.

The nonhuman agency of meetings can also be viewed through the ventriloquism metaphor presented by Cooren $(2010,2015 b)$. The meetings studied here are interunit and interprofessional, so it is taken that participants do not talk only on behalf of themselves but also on behalf of their unit or department and their profession. In particular, the chair often talks on behalf of hospital management, as he or she goes through the minutes of the health district's management group meetings. Thus, there are many ventriloquists at the same time at the same meeting. The findings of this study suggest that one of the ventriloquists is the meeting itself. The meeting makes the participants act and talk in a certain manner and on certain topics, sometimes in a play-like way. As Cooren (2015b) underlined, it is important to notice that ventriloquism goes both ways. Participants use the meeting as a ventriloquist's dummy, for example, when they want to make important issues official. The meeting, too, uses the participants as dummies, for example, when it makes the participants report on the same problems again and again.

Organizational vs. human agency and PT. The conclusions presented above highlight ways to examine PT from the viewpoints of the participants and the organization. 
The participants engage in PT because (a) they have their representative and formal roles as management group members and as managers or representatives of staff (the performative task), (b) they need solutions to the problems they are facing (the problem-solving task), and (c) they long for support, belonging, or position (the relational task). They do all this because of the meeting. From the viewpoint of the organization, PT in these meetings helps solve problems, keep the organization organized socially, and maintain the organization's structures by performing the meeting according to the organization's administrative rules. Thus, PT can emerge from the goals of the group or from the goals of the organization. This substantiates the argument that the meetings' agency falls on both the participants and the organization, or that meetings are both ventriloquists and dummies. Altogether, PT displays the agency of the meetings.

The above raises the following question: For whom is the task of PT conducted? It seems that the participants engage in PT because of their goals and the organization's goals, or in other words, both the human agency of the participants and the nonhuman agency of the organization or meeting are visible in PT. In particular, the performative task is often conducted for the organization. For example, problems were reported for the meetings' sake in the part of the meeting agenda addressing current issues. In addition, PT emerged from the need to have something mentioned in the meeting minutes in line with what the organization expects. For future research, it would be worth examining how this interplay of PT between for the participants and for the organization is done in formal group meetings or whether it exists in different organizational contexts. By examining for whom PT is executed and, therefore, focusing on both human and nonhuman agencies, the group's dynamic 
interdependence with its context (see Stohl, 2007; Stohl \& Putnam, 2003) could be studied in a novel way.

The findings also suggest that some tension exists between these two agencies because of the groups' powerlessness. For example, PT could be performed to get an issue mentioned in the meeting minutes (nonhuman agency being more dominant), but at the same time, the group could have problem-solving discussion even if the problem is not theirs to solve (human agency being more dominant). Many times, the problem itself, the accountability for the problem, or the solution for the problem was situated elsewhere and not in the groups' operational environments. Future research should focus on the tension between the human and nonhuman (organizational) agencies. For example, this tension could be examined from the viewpoints of accountability and power: When and how the group assigns accountability to itself, as well as when and how the group outsources the accountability to an outside nonhuman agent (see Castor \& Cooren, 2006; Stohl, 2007). Interview data would also be a useful addition to this approach.

\section{Naturalistic Research and Problem Solving}

The results substantiate the argument for studying groups in their natural environments. PT is complex and should be approached as such. Previous studies have shown that problem solving or decision making is often not the main function of group life (e.g., Scheerhorn, Geist, \& Teboul, 1994). The present study adds to this knowledge by showing that even PT is not always centered on solving problems (see also Leighter \& Black, 2010). This research demonstrates how the shared understanding of a problem and sometimes the solution for this problem is constructed in many places in a temporally diffused way and through the permeable boundaries of many groups. Thus, in small group research focusing on 
problem solving or PT, it could be useful to connect the CCO approach to the bona fide group perspective; this could be useful because organizational problem-solving processes are scattered temporally, spatially, and strategically (Putnam \& Stohl, 1990; Stohl \& Putnam, 2003).

The results affirm at least three issues with laboratory experiments concerning (a) context (Huisman, 2001; Putnam \& Stohl, 1990), (b) the temporal essence of problems (Kwon, Clarke, \& Wodak, 2009; Mintzberg, Raisinghani, \& Théorêt, 1976), and (c) the types of problems (Angouri \& Bargiela-Chiappini, 2011; Tracy \& Standerfer, 2003) from the viewpoint of working-life groups. The interdependence of the group with its context was evident as the groups discussed the current issues of the hospital, planned strategies for future meetings, and suffered from powerlessness. The temporal diffusion of the organizational problems was evident because some of the problems reported were ongoing, some were current, and some were in progress. Although the current study did not focus on describing different kinds of problems, the results show that the types of problems involved and the seriousness of these problems are more diverse than what they appear in existing experimental literature; they also include problems that the group can or cannot solve, problems that are local or global, problems that are simple or complex, and problems that are here and now or continuing. Future research on problem solving in natural groups should account for the many roles of PT and the multiple agents provoking such a talk. Overall, research focusing on meetings in organizations still has a lot to reveal. 


\section{References}

Allen, J. A., Lehmann-Willenbrock, N., \& Rogelberg, S. G. (2015). Introduction to the Cambridge handbook of meeting science. Why now?. In J. A. Allen, N. LehmannWillenbrock, \& S. G. Rogelberg (Eds.), The Cambridge handbook of meeting science (pp. 3-11). New York, NY: Cambridge University Press.

Angouri, J., \& Bargiela-Chiappini, F. (2011). 'So what problems bother you and you are not speeding up your work?' Problem solving talk at work. Discourse \& Communication, 5, 209-229. doi:10.1177/1750481311405589

Bargiela-Chiappini, F., \& Harris, S. (1997). Managing language: The discourse of corporate meetings. Amsterdam: The Netherlands: John Benjamins.

Beck, S. J., Bourdeaux, R., DiTunnariello, N., \& Paskewitz, E. A. (2016). A review and technological consideration of the bona fide group perspective. Small Group Research, 47, 665-691. doi:10.1177/1046496416665703

Blaschke, S., Schoeneborn, D., \& Seidl, D. (2012). Organizations as networks of communication episodes: Turning the network perspective inside out. Organization Studies 33, 879-906. doi:10.1177/0170840612443459

Boden, D. (1994). The business of talk: Organization in action. Cambridge, UK: Polity Press.

Boren, J. P. (2014). The relationships between co-rumination, social support, stress, and burnout among working adults. Management Communication Quarterly, 28, 3-25. doi:10.1177/0893318913509283

Braun, V., \& Clarke, V. (2006). Using thematic analysis in psychology. Qualitative Research in Psychology, 3(2), 77-101. doi:10.1191/1478088706qp063oa 
Brummans, B. H. J. M., Cooren, F., Robichaud, D., \& Taylor, J. R. (2014). Approaches to the communicative constitution of organizations. In L. L. Putnam \& D. K. Mumby (Eds.), SAGE handbook of organizational communication: Advances in theory, research, and methods (pp. 173-194). Thousand Oaks, CA: Sage.

Carcasson, M., \& Sprain, L. (2016). Beyond problem solving: Reconceptualizing the work of public deliberation as deliberative inquiry. Communication Theory, 26, 41-63. doi:10.1111/comt.12055

Castor, T. R. (2005). Constructing social reality in organizational decision making: Account vocabularies in a diversity discussion. Management Communication Quarterly, 18, 479-508. doi:10.1177/0893318904273689

Castor, T. (2007). Language use during school board meetings: Understanding controversies of and about communication. The Journal of Business Communication, 44, 111-136. doi:10.1177/0021943606298828

Castor, T., \& Cooren, F. (2006). Organizations as hybrid forms of life: The implications of the selection of agency in problem formulation. Management Communication Quarterly, 19, 570-600. doi:10.1177/0893318905284764

Cooren, F. (Ed.) (2007). Interacting and organizing: Analyses of a management meeting. Mahwah, NJ: Lawrence Erlbaum.

Cooren, F. (2010). Action and agency in dialogue: Passion, incarnation and ventriloquism. Amsterdam, The Netherlands: John Benjamins.

Cooren, F. (2015a). Organizational discourse: Communication and constitution. Cambridge, UK: Polity Press. 
Cooren, F. (2015b). Studying agency from a ventriloqual perspective. Management Communication Quarterly, 29, 475-480. doi:10.1177/0893318915584825

Cooren, F. (2018). Acting for, with, and through: A relational perspective on agency in MSF's organizing. In B. H. J. M. Brummans (Ed.), The agency of organizing. Perspectives and case studies (pp. 142-169). New York, NY: Routledge.

Cooren, F., \& Fairhurst, G. (2009). Dislocation and stabilization: How to scale up from interactions to organization. In L. L. Putnam \& A. M. Nicotera (Eds.), Building theories of organization. The constitutive role of communication (pp. 117-152). New York, NY: Routledge.

Craig, R. T., \& Tracy, K. (2005). The "issue" in argumentation practice and theory. In F. H. VanEemeren \& P. Houtlosser (Eds.), The practice of argumentation (pp. 11-28). Amsterdam: John Benjamins.

Dewey, J. (1910). How we think. Boston, MA: D. C. Heath.

Dewey, J. (1933). How we think. A restatement of the relation of reflective thinking to the educative process. Boston, MA: D. C. Heath.

Duffy, M. (2016). The agency of meetings as systemic process in the constitution of organizations: Insights from a longitudinal study and bifocal analysis of an organizations meetings (Doctoral thesis). Dublin Institute of Technology. doi:10.21427/D7R88T

Duffy, M. F., \& O'Rourke, B. K. (2015). A systemic view of meetings: Windows on organization collective minding. In J. A. Allen, N. Lehmann-Willenbrock, \& S. G. Rogelberg (Eds.), The Cambridge handbook of meeting science (pp. 223-246). New York, NY: Cambridge University Press. 
Evans, G. (2017). Minutes, meetings, and 'modes of existence': Navigating the bureaucratic process of urban regeneration in East London. In H. Brown, A. Reed, \& T. Yarrow (Eds.), Meetings. Ethnographies of organizational process, bureaucracy, and assembly [Special issue]. Journal of the Royal Anthropological Institute 23(S1), 125137. doi:10.1111/1467-9655.12598

Fairhurst, G. T., \& Uhl-Bien, M. (2012). Organizational discourse analysis (ODA): Examining leadership as a relational process. The Leadership Quarterly, 23, 10431062. doi:10.1016/j.leaqua.2012.10.005

Freeman, T., \& Peck, E. (2007). Performing governance: A partnership board dramaturgy. Public Administration, 85, 907-929. doi:10.1111/j.1467-9299.2007.00683.x

Frey, L. R. (1996). Remembering and "re-membering": A history of theory and research on communication and group decision making. In R. Y. Hirokawa \& M. S. Poole (Eds.), Communication and group decision-making (2nd ed., pp. 19-51). Thousand Oaks, CA: Sage

Frey, L. R., Botan, H. C., \& Kreps, G. L. (2000). Investigating communication: Introduction and research methods (2nd ed.). Boston, MA: Allyn and Bacon.

Gerding, J. M., \& Vealey, K. P. (2017). When is a solution not a solution? Wicked problems, hybrid solutions, and the rhetoric of civic entrepreneurship. Journal of Business and Technical Communication, 31, 290-318. doi:10.1177/1050651917695538

Gouran, D. S., \& Hirokawa, R. Y. (1996). Functional theory and communication in decisionmaking and problem-solving groups: An expanded view. In R. Y. Hirokawa \& M. S. Poole (Eds.), Communication and group decision-making (2nd ed., pp. 55-80). Thousand Oaks, CA: Sage. 
Gouran, D. S., \& Hirokawa, R. Y. (2003). Effective decision making and problem solving in groups: A functional perspective. In R. Y. Hirokawa, R. S. Cathcart, L. A. Samovar, \& L. D. Henman (Eds.), Small group communication: Theory and practice (pp. 2738). Los Angeles, CA: Roxbury Publishing Company.

Halvorsen, K. (2010). Team decision making in the workplace: A systematic review of discourse analytic studies. Journal of Applied Linguistics and Professional Practice, 7, 273-296. doi:10.1558/japl.v7i3.273

Hirokawa, R. Y., \& Poole, M. S. (1996). Communication and group decision making (2nd ed.). Thousand Oaks, CA: Sage.

Hoelscher, C. S., Kramer, M. W., Nguyen, C., Cooper, O. D., \& Day, E. A. (2016). Decision making and communication in a statewide interagency task force: An investigation of planned versus utilized processes. Management Communication Quarterly, 31, 39-68. doi:10.1177/0893318916661762

Hollingshead, A. B., Costa, G. H., \& Beck, S. (2007). Motives and goals in context: A strategic analysis of information sharing in groups. In K. Fiedler (Ed.), Frontiers of social psychology: Social communication (pp. 257-280). New York, NY: Psychology Press.

Huisman, M. (2001). Decision-making in meetings as talk-in-interaction. International Studies of Management \& Organization, 31, 69-90. doi:10.1080/00208825.2001.11656821

Iedema, R., Degeling, P., \& White, L. (1999). Professionalism and organisational change. In R. Wodak \& C. Ludwig (Eds.), Challenges in a changing world: Issues in critical discourse analysis (pp. 127-155). Wien, Austria: Passagen Verlag. 
Kauffeld, S., \& Lehmann-Willenbrock, N. (2012). Meetings matter: Effects of team meetings on team and organizational success. Small Group Research, 43, 130-158. doi:10.1177/1046496411429599

Kauffeld, S., \& Meyers, R. (2009). Complaint and solution-oriented circles: Interaction patterns in work group discussions. European Journal of Work and Organizational Psychology, 18, 267-294. doi:10.1080/13594320701693209

Koschmann, M. A., \& McDonald, J. (2015). Organizational rituals, communication, and the question of agency. Management Communication Quarterly, 29, 229-256. doi: $10.1177 / 0893318915572386$

Kwon, W., Clarke, I., \& Wodak, R. (2009). Organizational decision-making, discourse, and power: Integrating across contexts and scales. Discourse \& Communication, 3, 273302. doi:10.1177/1750481309337208

Laapotti, T., \& Mikkola, L. (2016). Social interaction in management group meetings: A case study of Finnish hospital. Journal of Health Organization and Management, 30, 613629. doi:10.1108/JHOM-02-2015-0040

Latour, B. (2005). Reassembling the social: An introduction to actor-network-theory. New York, NY: Oxford University Press.

Laughlin, P. R. (2011). Group problem solving. Princeton, NJ: Princeton University Press.

Leighter, J. L., \& Black, L. (2010). "I'm just raising the question": Terms for talk and practical metadiscursive argument in public meetings. Western Journal of Communication, 74, 547-569. doi.10.1080/10570314.2010.512281

Lincoln, Y. S., \& Guba, E. G. (1985). Naturalistic inquiry. Newbury Park, CA: Sage. 
Mintzberg, H., Raisinghani, D., \& Théorêt, A. (1976). The structure of "unstructured" decision processes. Administrative Science Quarterly, 21, 246-275. doi: $10.2307 / 2392045$

Olien, J. L., Rogelberg, S. G., Lehmann-Willenbrock, N., \& Allen, J. A. (2015). Exploring meeting science: Questions and answers. In J. A. Allen, N. Lehmann-Willenbrock, \& S. G. Rogelberg (Eds.), The Cambridge handbook of meeting science (pp. 12-19). New York, NY: Cambridge University Press.

Peck, E., Perri 6, Gulliver, P., \& Towell, D. (2004). Why do we keep on meeting like this? The board as ritual in health and social care. Health Services Management Research, 17, 100-109. doi:10.1258/095148404323043127

Poole, M. S. (2013) Structuration research on group communication. Management Communication Quarterly, 27, 607-614. doi:10.1177/0893318913506265

Putnam, L. L. (2016). Issue framing. In C. R. Berger. \& M. E. Roloff (Eds.), The international encyclopedia of interpersonal communication. West Sussex, UK: Wiley. doi:10.1002/9781118540190.wbeic0177

Putnam, L. L., \& Fairhurst, G. T. (2015). Revisiting “Organizations as discursive constructions": 10 years later. Communication Theory, 25, 375-392. doi:10.1111/comt.12074

Putnam, L. L. \& Nicotera, A. M. (2009). Building theories of organization. The constitutive role of communication. New York, NY: Routledge.

Putnam, L. L., \& Stohl, C. (1990). Bona fide groups: A reconceptualization of groups in context. Communication Studies, 41, 248-265. doi:10.1080/10510979009368307 
Robinson, V. M. J., \& Timperley, H. S. (2007). The leadership of the improvement of teaching and learning: Lessons from initiatives with positive outcomes for students. Australian Journal of Education, 51, 247-262.

Scheerhorn, D., Geist, P., \& Teboul, J. C. B. (1994). Beyond decision making in decisionmaking groups: Implications of the study of group communication. In L. R. Frey (Ed.), Group communication in context: Studies of natural groups (pp. 247-262). Hillsdale, NJ: Lawrence Erlbaum.

Schoeneborn, D., Blaschke, S., Cooren, F., McPhee, R. D., Seidl, D., \& Taylor, J. R. (2014). The three schools of CCO thinking: Interactive dialogue and systematic comparison. Management Communication Quarterly, 28, 285-316. doi:10.1177/0893318914527000

Schreier, M. (2014). Qualitative content analysis. In U. Flick (Ed.), The SAGE handbook of qualitative data analysis (pp. 170-184). London: Sage.

Schwartzman, H. B. (1989). The meeting: Gatherings in organizations and communities. New York, NY: Plenum Press.

Schwartzman, H. B. (2015). There's something about meetings: The order and disorder in the study of meetings. In Allen, J. A., Lehmann-Willenbrock, N., \& Rogelberg, S. G. (Eds.), The Cambridge handbook of meeting science (pp. 735-745), New York, NY: Cambridge University Press.

Schwartzman, H. B. (2017). Conclusion: The meeting and the mirror. In J. Sandler, \& R. Thedvall (Eds.), Meeting ethnography: Meetings as key technologies of contemporary governance, development, and resistance (pp. 158-178). New York, NY: Routledge. 
Seibold, D. R., \& Meyers, R. A. (2007). Group argument: A structuration perspective and research program. Small Group Research, 38, 312-336. doi:10.1177/1046496407301966

Simonen, O., Viitanen, E., Konu, A., \& Blom, M. (2009). Effectiveness in politicaladministrative decision-making in specialized healthcare. Scandinavian Journal of Public Health, 37, 494-502. doi:10.1177/1403494809106503

Stohl, C. (2007). Bringing the outside in: A contextual analysis. In F. Cooren (Ed.), Interacting and organizing: Analyses of a management meeting (pp. 185-198). Mahwah, NJ: Lawrence Erlbaum.

Stohl, C., \& Putnam, L. L. (2003). Communication in bona fide groups: A retrospective and prospective account. In L. R. Frey (Ed.), Group communication in context: Studies of bona fide groups (2nd ed., pp. 399-414). Mahwah, NJ: Lawrence Erlbaum.

Tracy, K., \& Dimock, A. (2004). Meetings: Discursive sites for building and fragmenting community. In P. J. Kalbfleisch (Ed.), Communication yearbook 28 (pp. 127-165). Mahwah, NJ: Lawrence Erlbaum.

Tracy, K., \& Standerfer, C. (2003). Selecting a school superintendent: Sensitivities in group deliberation. In L. R. Frey (Ed.), Group communication in context: Studies of bona fide groups (2nd ed., pp. 109-134). Mahwah, NJ: Lawrence Erlbaum.

Viitanen, E., Virtanen, J. V., Kokkinen, L., Valkonen, T., Mikkola, L., \& Puolijoki, H. (2011). Sairaalan johtoryhmät kaipaavat kehittämistä [How effective are hospital management teams?]. Suomen Lääkärilehti, 66, 373-377. Retrieved from https://www.laakarilehti.fi/pdf/2011/SLL52011-373.pdf 
Wittenbaum, G. M., Hollingshead, A. B., \& Botero, I. C. (2004). From cooperative to motivated information sharing in groups: Moving beyond the hidden profile paradigm. Communication Monographs, 71, 286-310.

doi:10.1080/0363452042000299894 


\section{Author Biographies}

Tomi Laapotti, $\mathrm{PhD}$, is a postdoctoral researcher at the Department of Language and

Communication Studies, University of Jyväskylä, Finland. His research interests include communicative constitution of organizations, meetings, agency, and leadership in selfdirected teams.

Leena Mikkola, $\mathrm{PhD}$, is a Senior Lecturer at the Department of Language and

Communication Studies, University of Jyväskylä, Finland. Her research interests include leadership communication, workplace relationships, and interprofessional interaction in institutional organizations.

\footnotetext{
${ }^{i}$ Although problem solving is generally a more comprehensive process than decision making, which can refer solely to choosing among alternatives, this study focuses on problem solving, but it also cites studies on decision making because these two processes are sometimes used interchangeably and have been defined in many ways in existing literature (e.g., Gouran \& Hirokawa, 2003).
} 